\title{
Flick of the switch
}

\section{By Lev Osherovich, Senior Writer}

Researchers from The Rockefeller University have developed an antibody-engineering technique that increases the antitumor potency of an agonistic anti-CD40 mAb. ${ }^{1}$ The method involves switching Fc $\gamma$-receptor IIb, an antibody co-receptor that binds to the invariant region of antibodies, from an inhibitor to a promoter of immune cell activation.

Jeffrey Ravetch, professor of molecular genetics and immunology at Rockefeller, and postdoctoral associate Fubin Li had been looking for ways to optimize antibody-dependent cellular cytotoxicity (ADCC), a process that involves activation of cytotoxic $\mathrm{T}$ cells and is thought to partially account for the action of many tumor-targeting mAbs.

To ramp up ADCC, the researchers tested the involvement of various Fc $\gamma$-receptors, which are found on the surface of immune cells, in the process. Whereas most of these receptors stimulate the innate immune response, Fc $\gamma$-receptor IIb (CD32B; FCGR2B) is an outlier-its downstream effects counteract immune cell activation.

Surprisingly, the researchers found that engaging FCGR2B was the key to the best ADCC. They showed that modifying a CD40activating $\mathrm{mAb}$ to tightly bind FCGR2B inverts the effect of FCGR2B's signal and leads to potent immunostimulation compared with conventional CD40-activating mAbs.

"The key novel finding is the unexpected observation that a [tumortargeting] antibody requires coengagement of the inhibitory Fc receptor."

- Jeffrey Ravetch, The Rockefeller University

Moreover, the CD40 mAb engineered for improved FCGR2B binding stimulated tumor immunity even more potently than CD40 $\mathrm{mAbs}$ engineered for increased binding to activating Fc receptors.

Results were reported in Science.

"The key novel finding is the unexpected observation that a [tumor-targeting] antibody requires coengagement of the inhibitory Fc receptor" for maximal effect, said Ravetch. "This is surprising because we previously understood that the function of this inhibitory Fc receptor was to gate or attenuate the response of stimulatory receptors. An inhibitory receptor that previously functioned only to reduce signaling could have a flip side promoting immune response."

\section{ADCC on tour}

If the group's mouse experiments translate to humans, CD40agonizing mAbs with better FCGR2B binding activity could represent an alternative to conventional CD40-agonizing mAbs in development as cancer immunotherapeutics.

"With this paper, it should be possible to tremendously improve the biological effect of CD40 mAbs" by combining a CD40-agonizing $\mathrm{mAb}$ with an engineered FCGR2B-binding site, said Bassil Dahiyat, president and CEO of Xencor Inc.

Xencor's XmAb5485, a CD40-agonizing mAb, is in preclinical development for cancer. Dahiyat said XmAb5485 has moderately higher affinity for FCGR2B than conventional mAbs but does not bind FCGR2B as strongly as Ravetch's engineered $\mathrm{mAb}$.

Earlier this year, Xencor granted Amgen Inc. an option to license another molecule, $\mathrm{XmAb5871}$, a mAb against CD19 engineered for stronger FCGR2B binding. The $\mathrm{mAb}$ is in preclinical development for B cell-mediated autoimmune disease.

According to Dahiyat, the company saw evidence of stimulatory effects by FCGR2B in

CD40 is a member of the tumor necrosis factor receptor family and is expressed on both innate immune cells and certain tumor cells. Both agonistic and antagonistic mAbs against CD40 have been tested as cancer therapeutics.

Compared with wild-type mice, animals lacking Fcgr2b were unable to mount an immune response against a model antigen when treated with a CD40-activating $\mathrm{mAb}$.

The researchers reasoned that Fcgr2b was important for the immunostimulatory effects of the CD40 mAb and went on to design a series of mutant $\mathrm{mAbs}$ that bound to Fcgr2b with affinity ranging from higher to lower than that of the original antibody. Engineered $m A b s$ with higher affinity were better at eliciting immune activation than the starting $\mathrm{mAb}$, whereas $\mathrm{mAb}$ with lower affinity were worse.

Additional evidence for the importance of FCGR2B came from experiments with a humanized mouse model of melanoma. A CD40agonizing $\mathrm{mAb}$ engineered for improved binding to human FCGR2B in transgenic mice increased both ADCC and survival compared with conventional CD40-agonizing mAbs. previous in vitro cancer studies but instead focused on the receptor's inhibitory activity as an autoimmune disease strategy.

Dahiyat said the company might now take a closer look at further enhancing FCGR2B binding for XmAb5485 or other cancer mAbs in light of the Rockefeller findings.

CD40-agonizing $\mathrm{mAbs}$ in the clinic include Pfizer Inc.'s CP-870893, which is in Phase I testing for cancer.

\section{Highway to well}

It remains to be seen what effect Ravetch's enhancements to FCGR2B binding would have on mAbs that antagonize CD40.

"There are several antibodies in clinical development that directly kill the tumor cells" by antagonizing CD40, said Ravetch, who sits on Xencor's scientific advisory board. "But these aren't very effective. It wasn't clear how these antibodies killed tumor cells, and they had only very modest potency in patients."

For example, dacetuzumab (SGN-40), a CD40-antagonizing mAb 


\section{ANALYSIS}

from Seattle Genetics Inc., failed a Phase IIb trial in relapsed or refractory diffuse large B cell lymphoma in 2009. The company has since discontinued development of the molecule.

Novartis AG and Xoma Ltd. have lucatumumab (HCD122), a CD40-antagonizing $\mathrm{mAb}$, in Phase I/II trials for non-Hodgkin's lymphoma (NHL) and is slated to enter a Phase I trial for follicular lymphoma this year.

Ravetch's team is now trying to tease out the signaling pathways triggered by CD40 mAbs that have improved FCGR2B binding.

He also suspects that the stimulatory effect of FCGR2B could increase the efficacy of other cancer mAbs. He plans to test whether FCGR2B is involved in the activity of agonistic mAbs against other tumor necrosis factor receptor homologs besides CD40.

Rockefeller University has filed for a patent on modulating agonistic tumor necrosis factor receptor $\mathrm{mAbs}$ and is seeking to out-license the IP.
Osherovich, L. SciBX 4(36); doi:10.1038/scibx.2011.1007 Published online Sept. 15, 2011

\section{REFERENCES}

1. Li, F. \& Ravetch, J.V. Science; published online Aug. 19, 2011; doi:10.1126/science.1206954

Contact: Jeffrey V. Ravetch, The Rockefeller University, New York, N.Y.

e-mail: ravetch@rockefeller.edu

\section{COMPANIES AND INSTITUTIONS MENTIONED}

Amgen Inc. (NASDAQ:AMGN), Thousand Oaks, Calif. Novartis AG (NYSE:NVS; SIX:NOVN), Basel, Switzerland Pfizer Inc. (NYSE:PFE), New York, N.Y.

The Rockefeller University, New York, N.Y. Seattle Genetics Inc. (NASDAQ:SGEN), Bothell, Wash. Xencor Inc., Monrovia, Calif.

Xoma Ltd. (NASDAQ:XOMA), Berkeley, Calif. 